\title{
Perceived and Preferred Interviewer Characteristics in Selection Interview
}

\author{
Najib Ahmad Marzuki ${ }^{1}$ \\ ${ }^{1}$ School of Social Development, Universiti Utara Malaysia, Sintok, Kedah, Malaysia \\ Correspondence: Najib Ahmad Marzuki, School of Social Development, Universiti Utara Malaysia, 06010 \\ Sintok, Kedah, Malaysia. Tel: 60-13-430-0770. E-mail: najib320@uum.edu.my
}

\author{
Received: August 5, 2013 Accepted: October 30, 2013 Online Published: December 31, 2013 \\ doi:10.5539/ass.v10n1p165 \\ URL: http://dx.doi.org/10.5539/ass.v10n1p165
}

\begin{abstract}
Perceptions of interviewer characteristics signify the validity and reliability of selection procedures. Personality characteristics of the interviewer such as personableness, skills and competency, questioning manner and job information may be perceived differently in different situations. This study examined the perceived and preferred interviewer characteristics based on Perceived Interviewer Characteristics Scale by Ahmad Marzuki (2000). In addition, it included the preferred interviewer characteristics scales modified from the original scales. A total of 140 participants were selected as samples. Results indicated that the actual 4 scales except for 'questioning manner' characteristic were correlated to the preferred interviewer characteristics. Results also shown that there were significant differences between what the applicants perceived and what the applicants preferred in three interviewer characteristics namely personableness, skills and competency and job information in general, as well as based on those who were offered and not offered the job.
\end{abstract}

Keywords: personableness, skills and competency, questioning manner, job information

\section{Introduction}

To most people, employment represents an important aspect of their lives (Schein, 1982). Therefore, applicants are expected to be concerned with selection processes and procedures. Joining an organization through a selection process is actually a public expression of the applicant's own personal characteristics (Spector, 2012). In the personnel selection literature, the use of personality measurement has been extensively focused on its use for decision-making (Aamodt, 2010; Arnold \& Randall, 2010; Robertson, 1994) including as predictor of job performance (Barrick \& Mount, 1991; Salgado, 1997; Salgado \& Rumbo, 1997; Tett, Jackson \& Rothstein, 1991). The use of personality characteristics to relate perceptions of interviewer characteristics in selection interview, however, has not been examined before. Hence, one of the objectives of this study is to investigate the associations of perceived and preferred interviewer characteristics in the interview session.

Although there has been no research to directly explore links between applicants' personality and their perceptions of interviewer characteristics, evidence which indicates that applicants are attracted to work environments that are compatible with their personal characteristics has been found in the job and organizational choice literature (Kristof, 1996). In addition, research has indicated that a person's work values are shaped by a number of factors including education and career choices (Kohn \& Schooler, 1978) and organizational socialization experiences (Chatman, 1991). In the selection interview context, an antecedent of applicants' work values is personality (Muchinsky, 2006; Riggio, 2008). They are stable, innate mental structure which provides general direction for their choices or behaviour (Hogan, 1991). Therefore, personality should have an effect on the perceptions they made towards individuals.

The interviewer characteristics are related to selection interview in such a way that the personableness of the conduct is related to personality in general terms. The other characteristics are skills and competency, questioning manner and job information. All these characteristics were based on previous studies by researchers (Ahmad Marzuki, 2000).

Previous research had focused on expectations regarding what will be discussed by the interviewer in the interview. For example, Herriot and Rothwell $(1981,1983)$ have found out that there are some differences regarding what the applicants' expect of the interviewer and their actual experience in the interview. In addition, 
studies on pre and post interview impressions have also been done but have been examined from the interviewer's perspectives and not applicants' (Dipboye, Stramler \& Fontennelle, 1984; Macan \& Dipboye, 1990; Phillips \& Dipboye, 1989).

Even though these studies focused on evaluations of the selection interview, they did not directly link to applicants' impressions of interviewer characteristics. The main idea that can be derived from previous work was that there exists some form of preference in terms of what might take place in the selection process. Based on these criteria, a section to measure the preferred interviewer characteristics in the interview was included in order to determine whether there exists any association between perceived and preferred interviewer characteristics. When the actual perceptions of an interviewer's characteristics and the preferences are measured together, it is assumed that the higher the perceptions of interviewer characteristics, the higher the preferences will be. The perceptions of actual interviewer characteristics are assumed to be related to their preferences of interviewer characteristics in a sense that perceptions of earlier events (measures of actual interviewer characteristics) may influence later events (measures of preferences).

\section{Methods}

\subsection{Participants}

Participants in this study were undergraduate and postgraduate students from a public university gathered through simple random sampling. One hundred and fifty questionnaires were distributed and returned. Ten participants were deleted from the sample for two reasons: seven of the questionnaires had not been fully completed (more than 50 percent missing values) by the participants while three has been returned uncompleted. Out of the 140 participants, 94 were undergraduate students (39 males and 55 females) and 46 postgraduate students ( 24 males and 22 females). Their ages ranged from 18 to 35 years (mean $=22.4, \mathrm{SD}=3.98)$ with prior interview experience between 1 to 25 interviews (mean $=3.90$ ).

\subsection{Instruments}

The perceived interviewer characteristics' scale (the 4 scales) by Ahmad Marzuki (2000) measured Personableness, Skills and Competency, Questioning Manner and Job Information was used . Items comprised brief descriptions of behaviour or characteristics of the interviewer. Ratings were made on a 5 point Likert-type scale $(1=$ strongly disagree, $5=$ strongly agree $)$ indicating the degree to which the interviewer exhibited the characteristics.

In this study, a section was included in the questionnaire to measure applicants' preferred interviewer characteristics. The aim of this section was to determine whether there was any relationship between individual's perceived and preferred characteristics of the interviewer in the interview.

Four items from each perceived interviewer characteristics' scale (4 scales) were selected and modified to represent statements of applicants' preferred interviewer characteristics. Ratings were also made on a 5 point Likert-type scale $(1=$ most unprefer, $5=$ most prefer $)$.

\section{Results and Discussion}

The perceived and preferred interviewer characteristics of the participants were analyzed through correlations. Results (Table 1) indicate that the actual 4 scales (perceived interviewer characteristics) were significantly correlated to the preferred 4 scales except for Questioning Manner $(r=-0.01, p>.05)$. Perceived characteristics in the interview were associated with the likelihood of preferred or ideal interviewers (Personable, $r=0.31, p$ $<.001$; Skills and Competency, $\mathrm{r}=0.25, \mathrm{p}<.01$; Job Information, $\mathrm{r}=0.34, \mathrm{p}<.001$ ). Overall, the more the participants perceived the interviewer characteristics in the actual interview the more preferences they have regarding the interviewer characteristics they expect or hope to be shown in any interview. The result of the correlations support earlier hypothesis that the preferred interviewer characteristics will be positively correlated to the perceived characteristics of the interviewer although the scale "Preferred and Perceived Questioning Manner" was found to be non-correlated to each other. 
Table 1. Means, standard deviations and intercorrelations of perceived and preferred interviewer characteristics' scales

\begin{tabular}{|c|c|c|c|c|c|c|c|c|c|}
\hline Variable & $\mathrm{M}$ & SD & 1 & 2 & 3 & 4 & 5 & 6 & 7 \\
\hline 1. Personable & 60.91 & 10.86 & & & & & & & \\
\hline 2. Skills and Competency & 52.85 & 9.22 & $0.43^{* * *}$ & & & & & & \\
\hline 3. Questioning Manner & 23.00 & 4.25 & $0.48 * *$ & 0.04 & & & & & \\
\hline 4. Job Information & 13.77 & 3.79 & $0.24 * *$ & $0.32 * * *$ & 0.04 & & & & \\
\hline 5. Pref. Personable & 13.31 & 1.87 & $0.31 * * *$ & 0.10 & $0.18 *$ & $0.17 *$ & & & \\
\hline $\begin{array}{l}\text { 6. Pref. Skills and } \\
\text { Competency }\end{array}$ & 16.28 & 3.14 & $0.21^{*}$ & $0.25 * *$ & 0.11 & 0.12 & 0.11 & & \\
\hline 7. Pref. Questioning Manner & 15.12 & 3.06 & -0.12 & -0.16 & -0.01 & -0.07 & -0.01 & -0.15 & \\
\hline 8. Pref. Job Information & 11.73 & 2.16 & $0.25 * *$ & 0.15 & $0.21 *$ & $0.34 * * *$ & $0.23 * *$ & $0.21 * *$ & -0.11 \\
\hline
\end{tabular}

Key: Pref. $=$ Preferred

\subsection{Perceptual Differences between Perceived and Preferred 4 Scales}

Apart from the association found between the perceived and preferred interviewer characteristics' scales, it is imperative to investigate whether any perceptual differences exist between each scale. As such, the score for each characteristic (Personableness, Skills and Competency, Questioning Manner and Job Information) in each scale (Preferred and Perceived) was transformed into mean percentages and compared to each other. Positive difference between each scale indicates that preferences of the particular interviewer characteristics have been met while negative difference indicates that preferences of the particular interviewer characteristic have not been met. The differences for each scale are presented in Table 2.

Table 2. Mean percentage differences between perceived and preferred 4 scales

\begin{tabular}{lllll}
\hline & Personableness & Skills and Competency & Questioning Manner & Job Information \\
\hline Perceived Scale (\%) & 71.66 & 70.48 & 76.67 & 68.86 \\
Preferred & Scale & $(\%)$ & 88.76 & 81.43 \\
Differences (\%) & $17.10^{* * *}$ & 10.95 & +1.03 & $9.38^{* * *}$ \\
\hline
\end{tabular}

$* * * \mathrm{p}<.001$

Looking at Table 2, it was found that preferences on personableness factor, skills and competency and job informativeness were not met. Only preferences on the questioning manner scale was met.

\subsection{Significant Differences between Perceived and Preferred Interviewer Characteristics}

The findings in Table 2 were followed by a paired samples t-test between the perceived and preferred 4 scales to examine significance differences in the four characteristics. Results indicated that there were significant differences between what the applicants perceived and what the applicants preferred in three interviewer characteristics (see Table 2 - indicated by asterisk). These significant differences were found in Personableness ( $\mathrm{t}$ $=-13.65$, d.f. $=139, \mathrm{p}<.001)$, Skills and Competency $(\mathrm{t}=-7.48$, d.f. $=139, \mathrm{p}<.001)$ and Job Information $(\mathrm{t}=$ -5.72 , d.f. $=139, \mathrm{p}<.001)$. The differences in these three characteristics were found to be negative indicating higher preferences in interviewer characteristics compare to the perceptions of actual interviewer characteristics. The difference on the "Questioning Manner" characteristic, however, was found to be non-significant $(\mathrm{t}=0.57$, d.f. $=139, \mathrm{p}>.05)$.

\subsection{Significant Differences for the i) Perceived and ii) Preferred Interviewer Characteristics}

To determine whether there was any significant main effects within subjects on the i) perceived and ii) preferred interviewer characteristics, multivariate analysis of variance was conducted (see Table 2 - horizontally). Results showed that there were significant main effects for perceived $(F=7.72$, d.f. $=3,137, p<.001)$ and preferred 
interviewer characteristics $(\mathrm{F}=30.10$, d.f. $=3,137, \mathrm{p}<.001)$. These findings implied that perceptual differences along the 4 scales in both perceived and preferred interviewer characteristics were significant. For the perceived interviewer characteristics' scales, Questioning Manner was highly rated (76.67\%) compared to Personable, Skills and Competency and Job Information while for preferred interviewer characteristics' scales, the Personableness $(88.76 \%)$ of the interviewer was highly preferred compared to Skills and Competency, Questioning Manner and Job Information.

\subsection{Perceptual Differences between Participants Who Were Offered and Not Offered the Job}

Participants who were offered and not offered the job they applied for may differ in their perceptions between what they perceived in the actual interview and what they actually prefer from an interviewer. Therefore, mean percentage differences were calculated for the scores in each scale of these two groups (those who were offered and those who were not offered the job).

Preferences for all participants, irrespective of whether they got the job or not were not met in all scales except in Questioning Manner for those who got the job (Table 3). Looking at the differences in percentages, the preferences of participants who were offered the job, however, were found to be less likely to be met in the actual perceived interviewer characteristics (except for Skills and Competency) compared to those who were offered the job as indicated by the high negative mean percentages' differences.

Table 3. Mean percentage differences between perceived and preferred 4 scales for those who were offered and not offered the job

\begin{tabular}{lllllllll}
\hline & \multicolumn{2}{l}{ Personableness } & \multicolumn{2}{l}{ Skills and Competency } & \multicolumn{2}{l}{ Questioning Manner } & \multicolumn{2}{l}{ Job Information } \\
\hline & WO & NO & WO & NO & WO & NO & WO & NO \\
Perceived Scale (\%) & 72.83 & 63.79 & 70.54 & 70.07 & 77.84 & 68.70 & 69.71 & 63.06 \\
Preferred Scale (\%) & 89.18 & 85.93 & 82.21 & 76.11 & 75.08 & 79.44 & 78.47 & 76.67 \\
Differences (\%) & $16.35^{* * *}$ & $22.14^{* * *}$ & $11.67^{* * *}$ & 6.04 & +2.76 & $-10.74^{*}$ & $-8.76^{* * *}$ & $-13.61^{*}$ \\
\hline
\end{tabular}

$* \mathrm{p}<.05, * * * \mathrm{p}<.001$

Key: $\mathrm{WO}=$ were offered

$\mathrm{NO}=$ were not offered

\subsection{Significant Differences between Perceived and Preferred Interviewer Characteristics for Those Who Were Offered and Not Offered the Job}

To examine whether the differences in mean percentage between perceived and preferred interviewer characteristics were significant or not, paired samples t-test were conducted and found that all the above differences (Table 3) were significant except for differences in the "Questioning Manner" for those who did get the job $(\mathrm{t}=1.45$, d.f. $=121, \mathrm{p}>.05)$ and in "Skills and Competency" $(\mathrm{t}=1.01$, d.f. $=17, \mathrm{p}>.05)$ for those who did not get the job (see Table 4.5 - asterisk).

\subsection{Significant Difference for the i) Perceived and ii) Preferred Interviewer Characteristics for Those Who Were Offered and Not Offered the Job}

Multivariate analysis of variance conducted on the combined dependent variables of perceived Personable, Skills and Competency, Questioning Manner and Job Information found that being offered or not being offered the job has a significant main effects through the Hotellings's $F$ test $(F=3.12$, d.f. $=4,135, p<.05)$. This was followed by a univariate analysis of variance which showed that the significant main effect was attributable to Personableness $(\mathrm{F}=8.24$, d.f. $=1,138, \mathrm{p}<.01)$ and Questioning Manner $(\mathrm{F}=6.78$, d.f. $=1,138, \mathrm{p}<.05)$. This indicates that participants who were offered the job perceived the interviewer as more personable and have better questioning style than those who were not offered the job (see Table 4.5 - horizontally). It also means that perceptions of actual interviewer characteristics were affected by outcome of the interview (offered or not being offered the job)

However, multivariate analysis of variance on the combined dependent variables of preferred Personable, Skills and Competency, Questioning Manner and Job Information has come out with a non-significant main effects on the Hotellings's test $(\mathrm{F}=0.98$, d.f. $=4,135, \mathrm{p}>.05)$. The result revealed that there was no significant difference in participants' preferences of interviewer characteristics irrespective of whether they being offered the job or not 
(see Table 3 - horizontally). Preferred interviewer characteristics were not affected whether they got the job or not.

It was assumed that participants who were offered the job will have positive differences in mean percentage scores (high positive perceptions of actual interviewer characteristics and low preferences) while those who were not offered the job will have negative differences in mean percentage scores (low positive perceptions of interviewer characteristics and high preferences). Looking at the percentage differences in Table 4.5, participants who were not offered the job showed negative differences in mean percentage scores for all scales indicating that their preferences of interviewer characteristics were high. This also implies that their preferences were less met in the actual interview compared to those who were offered the job.

\section{Conclusion}

The inclusion of preferred interviewer characteristics' scales in this study was aimed at investigating any differences between perceived and preferred interviewer characteristics of participants who were offered a job after the interview and those who were not offered a job. It was found that participants who were not offered the job have higher mean percentages of interviewer characteristics preferences compared to perceptions of the actual interviewer characteristics in the interview, meaning that their preferences were not met in the actual interview. Similarly, participants who were offered the job also have higher rated preferences. However, the preferences of participants who were not offered the job were less met in the actual interview compared to those who were offered the job. It was expected for applicants to draw high preferences regarding the characteristics of the interviewer if the particular organization fails to offer the job as required by the participants. For those who got the job, they have lower preferences regarding interviewer characteristics since they were satisfied after being offered the job. Therefore, their preferences were not as high as those who did not get the job. Perceived interviewer characteristics were assumed to be affected by job offered when those who got the job rated the interviewer characteristics higher than those who did not get the job. This might be attributed to personal satisfaction after being offered the job.

\section{References}

Aamodt, M. G. (2010). Industrial/Organizational psychology: An Applied research. Belmont: Lengage Learning.

Ahmad Marzuki, N. (2000). Perceptions towards interviewer characteristics in selection interview. Proceeding of the Seminar in Psychology. Universiti Kebangsaan Malaysia, Bangi, Selangor Malaysia, 2-3 November 2000.

Arnold, J., \& Randall, R. (2010). Work psychology: Understanding human behavior in the workplace. Haslaw: Prentice Hall.

Barrick, M. A., \& Mount, M. K. (1991). The big five personality dimensions and job performance: A meta-analysis. Personnel Psychology, 44, 1-26. http://dx.doi.org/10.1111/j.1744-6570.1991.tb00688.x

Block, J. (1995). A contrarian view of the five-factor approach to personality description. Psychological Bulletin, 117(2), 187-215. http://dx.doi.org/10.1037/0033-2909.117.2.187

Chatman, J. (1991). Matching people to organizations: Selection and socialization in public accounting firms. Administrative Science Quaterly, 36, 459-484. http://dx.doi.org/10.2307/2393204

Dipboye, R. L., Stramler, C. S., \& Fontenelle, G. A. (1984). The effects of the application on recall of information from the interview. Academy of Management Journal, 27, 561-575. http://dx.doi.org/10.2307/256045

Goldberg, L. R. (1992). The development of markers for the Big-Five factor structure. Psychological Assessment, 4, 26-42. http://dx.doi.org/10.1037/1040-3590.4.1.26

Herriot, P., \& Rothwell, C. (1981). Organizational choice and decision theory: Effects of employers' literature and selection interview. Journal of Occupational Psychology, 54, 17-31. http://dx.doi.org/10.1111/j.2044-8325.1981.tb00041.x

Herriot, P., \& Rothwell, C. (1983). Expectations and impressions in the graduate selection interview. Journal of Occupational Psychology, 56, 303-314. http://dx.doi.org/10.1111/j.2044-8325.1983.tb00137.x

Hogan, R. (1991). Personality and personality measurement. In M. D. Dunnette, \& L. M. Hough (Eds.), Handbook of Industrial and Organizational Psychology (pp. 873-919). Palo Alto, California: Consulting Psychologists Press.

Kohn, M. L., \& Schooler, C. (1978). The reciprocal effects of the substantive complexity of work and 
intellectual flexibility: A longitudinal assessment. American Journal of Sociology, 84, 24-52. http://dx.doi.org/10.1086/226739

Kristof, A. L. (1996). Person-organization fit: An integrative review of its conceptualization, measurement and implications. Personnel Psychology, 49, 1-49. http://dx.doi.org/10.1111/j.1744-6570.1996.tb01790.x

Macan, T. H., \& Dipboye, R. L. (1988). The effects of interviewers' initial impressions on information gathering. Organizational Behavior and Human Decision Processes, 42, 364-387. http://dx.doi.org/10.1016/0749-5978(88)90006-4

Muchinsky, P. M. (2006). Psychology Applied to Work. Belmont, California: Wadsworth.

Phillips, A. P., \& Dipboye, R. L. (1989). Correlational tests of predictions from a process model of the interview. Journal of Applied Psychology, 74, 41-52. http://dx.doi.org/10.1037/0021-9010.74.1.41

Riggio, R. E. (2003). Introduction To Industrial/Organizational Psychology. New Jersey: Prentice Hall.

Robertson, I. T. (1994). Personality and personnel selection. In C. L. Cooper, \& D. M. Rousseau (Eds.), Trends in Organizational Behavior (pp. 75-89). Chichester: John Wiley \& Sons.

Salgado, J. F. (1997). The five-factor model of personality and job performance in the European community, Journal of Applied Psychology, 82(1), 30-43. http://dx.doi.org/10.1037/0021-9010.82.1.30

Salgado, J. F., \& Rumbo, A. (1997). Personality and job performance in financial services managers. International Journal of Selection and Assessment, 5(2), 91-100. http://dx.doi.org/10.1111/1468-2389.00049

Schein, E. H. (1982). Individuals and careers. In J. W. Lorsch (Ed.), Handbook of Organizational Behavior. Englewood cliffs, New Jersey: Prentice-Hall.

Spector, P. E. (2012). Industrial and organizational psychology: Research and practice. New York: John Wiley.

Tett, R. P., Jackson, D. N., \& Rothstein, M. (1991). Personality measures as predictors of job performance: A $\begin{array}{lllll}\text { meta-analytic } & \text { review. } & \text { Personnel } & \text { Psychology, } & 44,\end{array}$ http://dx.doi.org/10.1111/j.1744-6570.1991.tb00696.x

\section{Copyrights}

Copyright for this article is retained by the author(s), with first publication rights granted to the journal.

This is an open-access article distributed under the terms and conditions of the Creative Commons Attribution license (http://creativecommons.org/licenses/by/3.0/). 